\title{
Does delay in fixation affect the number of mitotic figures in processed tissue?
}

\author{
S S Cross, R D Start, J H F Smith
}

\begin{abstract}
The effect of delay in fixation on the number of mitotic figures in tissues has received little attention, and previous studies have reached differing conclusions. The numbers of mitotic figures in the normal mucosa of six colectomy specimens were counted with delays in fixation of 30 minutes, one hour, two hours, three hours and six hours for samples from each specimen. The numbers of mitotic figures were counted in $\mathbf{5 0}$ whole crypts in each specimen by two observers. All phases of mitosis were counted. The number of observable mitotic figures declined by about $30 \%$ with a delay in fixation of two hours and by $50 \%$ with a delay of six hours. This observation has important implications for the handling of surgical specimens.
\end{abstract}

In many tumours the number of mitotic figures seen in histological sections has a useful correlation with the biological behaviour of the tumour. Formal systems of counting mitotic figures are used in the diagnosis of malignancy in smooth muscle tumours of the uterus ${ }^{12}$ and as part of prognostic indices in breast carcinoma, ${ }^{34}$ thyroid carcinoma, ${ }^{5}$ and non-Hodgkin's lymphoma. ${ }^{6}$ Subjective assessment of mitotic figures is used in the diagnosis of many other tumours and in the grading of degrees of epithelial dysplasia.

There are several potential sources of error in the counting of mitotic figures. Counting must be carried out over defined areas in a prescribed pattern if an acceptable degree of consistency is to be achieved. ${ }^{7-12}$ One factor which has received relatively little attention is the effect of delayed or inadequate fixation. The investigations by Evans in the early part of this century showed no decline in the number of mitotic figures when fixation was delayed for 24 hours, but only two tumours were examined and environmental conditions were not carefully controlled..$^{13}$ Later studies by Bullough ${ }^{14}$ and Edwards and Donalson ${ }^{15}$ showed a sharp decline in the number of mitotic figures over the first 12 hours following removal. Both these studies were performed on murine tissues. A study on mitotic tissues in human cervical epithelium ${ }^{16}$ found no difference in the numbers of mitotic figures in specimens which were fixed immediately and those which were incubated at 20 or $37^{\circ} \mathrm{C}$ for up to two hours. Graem and Helweg-
Lârsen used a human osteogenic sarcoma grown in athymic nude mice as their experimental tissue. ${ }^{17}$ Their carefully controlled investigation showed an almost exponential decline in the number of mitotic figures when fixation was delayed for periods of up to three hours. Their study also recorded the number of mitotic figures in each different phase of mitosis and found that a relative accumulation of the advanced phases occurred with increased delay in fixation. The authors suggested that cells in early mitosis may complete that mitosis if fixation of tissue is delayed but that relatively few cells entered the mitotic phase of the cell cycle after removal of tissue.

The apparent differences in results between these studies and the relative paucity of work using human tissues suggested that further study was required to investigate the effect of delay in fixation on the number of mitotic figures in processed tissues.

\section{Methods}

Ten colectomy specimens for resection of colonic adenocarcinoma were received in the operating theatre directly after removal from patients. The surgeons noted the time at which the vessels to the colon were clamped and this was designated as time zero.

A length of macroscopically normal colon, distal to the tumour, was removed and divided into five equal parts. These parts were shuffled to prevent topological sampling bias and each part was placed in a separate plastic pot. The pots were kept at a constant temperature of $20^{\circ} \mathrm{C}$, a temperature which approximates to the average working temperature in our histological laboratory. At times of 30 minutes, one hour, two hours, three hours and six hours after vessel clamping $4 \%$ formaldehyde solution was added to one of the pots. It was found that 30 minutes after vessel clamping was the earliest time at which all specimens had been removed from the patient and divided into appropriate portions. Preliminary studies showed that autolysis precluded accurate assessment of mitotic figures in samples left unfixed for more than six hours. After a further period of 24 hours samples were taken from each pot and routinely processed into paraffin wax. Sections were cut at a constant thickness of $6 \mu \mathrm{m}$ and then stained with haematoxylin and eosin.

The total numbers of mitotic figures in $\mathbf{5 0}$ whole colonic crypts in each timed specimen 
Mean number of mitotic figures in 50 whole colonic crypts in specimens fixed at between 30 minutes and six hours after clamping of colonic vessels (figures in parentheses are percentage of number of mitotic figures in specimen fixed at 30 minutes)

\begin{tabular}{|c|c|c|c|c|c|}
\hline \multirow[b]{2}{*}{ Specimen } & \multicolumn{5}{|c|}{ Time between clamping of vessels and fixation (hours) } \\
\hline & $1 / 2$ & 1 & 2 & 3 & 6 \\
\hline $\begin{array}{l}\text { A } \\
\text { B } \\
\text { C } \\
\text { D } \\
\text { E } \\
\text { F }\end{array}$ & $\begin{array}{r}55(100) \\
51(100) \\
96(100) \\
78(100) \\
146(100) \\
177(100)\end{array}$ & $\begin{array}{r}43(78) \\
45(88) \\
81(84) \\
70(90) \\
87(60) \\
157(89)\end{array}$ & $\begin{array}{r}35(64) \\
27(53) \\
72(75) \\
64(82) \\
94(64) \\
118(67)\end{array}$ & $\begin{array}{l}36(65) \\
27(53) \\
56(58) \\
56(72) \\
86(59) \\
93(53)\end{array}$ & $\begin{array}{l}32(58) \\
24(47) \\
47(49) \\
37(47) \\
68(47) \\
87(49)\end{array}$ \\
\hline Mean & $101(100)$ & $81(80)$ & $68(68)$ & $59(58)$ & $49(49)$ \\
\hline
\end{tabular}

were counted independently by two observers (SSC and RDS). A whole crypt was defined as a crypt in which the whole length of the crypt, from the muscularis mucosae to the mucosal surface, could be visualised. This unit was used because mitotic figures are distributed unevenly through the length of a crypt, being more common at the base. ${ }^{18}$ Figures in all phases of mitosis were counted and care was taken to distinguish these from intraepithelial lymphocytes and pyknotic nuclei. The samples were counted in random temporal sequence and all windows on the counter were occluded, except that displaying the number of crypts counted. Four specimens were unsuitable for these observations due to either focal inflammation and ulceration or insufficient numbers of visualisable whole crypts. In the six remaining specimens the mean of the two observations was calculated. The distribution of the results was approximately Gaussian and the paired Student's $t$ test was used to assess significance of the results.

\section{Results}

The main results are presented in the table. The overall interobserver variation was $9.6 \%$. Although the number of mitotic figures in the 30 minute specimen showed considerable variation (range 51-177) the numbers declined at a similar rate in all six specimens. In the samples in which fixation was delayed for six hours the decline in the number of mitotic figures, when compared with the samples fixed at 30 minutes, was very similar (mean $49 \%$, range $47-58 \%$ ). This difference in the number at 30 minutes and six hours was significant $(0.001<\mathrm{p}<0.01)$.

\section{Discussion}

Our results show a decline in the number of observable mitotic figures of about $50 \%$ when fixation is delayed by six hours and of about $30 \%$ when fixation is delayed by two hours. These results are similar to those of three previous studies ${ }^{14-17}$ and confirm that this phenomenon occurs in a system using only normal human tissues.

These results emphasise the importance of prompt and efficient fixation of surgical specimens. Fixatives penetrate tissues at a rate equal to the square root of time multiplied by a coefficient of diffusability. ${ }^{1920}$ The tissue diffusability coefficient for $4 \%$ formaldehyde solution is $0 \cdot 78,{ }^{19} 20$ so in 24 hours it will only penetrate to a distance of about $3.8 \mathrm{~mm}$. It is evident that large specimens require slicing to ensure rapid and even fixation; this is particularly important in uteri containing smooth muscle tumours as these are often large and counting of mitotic figures is one of the primary factors used to predict benign or malignant behaviour. Any variation in procedures for fixing specimens could produce wide variation in the number of mitotic figures in otherwise similar tumours and result in inconsistencies in grading of these tumours. Examples encountered in our laboratory practice are breast excision biopsy and mastectomy specimens where some are sliced in theatre to expose the tumour to fixative whereas others are immersed intact in $4 \%$ formaldehyde solution and received in the laboratory after a delay of about 15 hours. As the tumour in the intact specimen is unlikely to have been penetrated by any fixative (because the tumour will usually be more than $3 \mathrm{~mm}$ distant from the resection margins) the number of mitotic figures will be less than half the number in an otherwise similar sliced tumour and any system of tumour grading which includes mitosis counting, such as that devised by Bloom and Richardson, ${ }^{3}$ will be invalidated.

This study has only investigated the effect of delayed fixation on mitotic figures in the colonic mucosa. Tissues with different metabolic requirements and different rates of cell turnover could show a greater or lesser decline in the number of mitotic figures. Further studies on solid tumours, especially those where mitosis counting is used in diagnosis or grading, are indicated to investigate this.

We thank Mr Ken Rogers and his surgical team for providing the specimens and $\mathrm{Mr}$ Clifford Lambourne and his MLSO staff for technical assistance.

1 Taylor HB, Norris HJ. Mesenchymal tumours of the uterus. IV. Diagnosis and prognosis of leiomyosarcomas. Archives of Pathology 1966;82:40-4.

2 Kempson RL, Bari W. Uterine sarcomas. Classification, diagnosis and prognosis. Hum Pathol 1970;1:331-49.

3 Bloom HJG, Richardson WW. Histological grading and prognosis in breast cancer. Br J Cancer 1957;11:359-77.

4 Fisher ER, Redmond C, Fisher B. Histologic grading of breast cancer. Pathol Annu 1980;15:239-51.

5 Lee T-K, Myers RT, Marshall RB, Bond G, Kardon B. The significance of mitotic rate: a retrospective study of 127 
thyroid carcinomas. Hum Pathol 1985;16:1042-6.

6 Akerman M, Brandt L, Johnson A, Olsson H. Mitotic activity in non-Hodgin's lymphoma. Relation to the Kiel classification and to prognosis. $B r J$ Cancer 1987;55: 219-23.

7 Silverberg SG. Reproducibility of the mitosis count in the histologic diagnosis of smooth muscle tumours of the uterus. Hum Pathol 1976;7:451-4.

8 Scully RE. Mitosis counting-I. Hum Pathol 1976;7:481-2. 9 Kempson RL. Mitosis counting-II. Hum Pathol 1976;7:482-3.

10 Norris HJ. Mitosis counting-III. Hum Pathol 1976;7: 483-4.

11 Ellis PSJ, Whitehead R. Mitosis counting - a need for reappraisal. Hum Pathol 1981;12:3-4.

12 Donhuijsen K. Mitosis counts: reproducibility and significance in grading of malignancy. Hum Pathol 1986;17:122-5.

13 Evans N. Mitotic figures in malignant tumors as affected by time before fixation of tissues. Arch Path Lab Med
1926;1:894-8.

14 Bullough W. Mitotic activity in the tissues of dead mice, and in tissues kept in physiological salt solutions. Exp Cell Res 1950;1:410-20.

15 Edwards JL, Donalson JT. The time of fixation and the mitotic index. Am J Clin Pathol 1964;41:158-62.

$16 \mathrm{Chi} \mathrm{CH}$, Rubio CA, Lagerlof $\mathrm{B}$. The frequency and distribution of mitotic figures in dysplasia and carcinoma in situ. tion of mitotic figures in dysplasia and carcinoma in situ.

17 Graem N, Helweg-Larsen K. Mitotic activity and delay in fixation of tumour tissue. Acta Pathol Microbiol Scand (Sect $A$ ) $1979 ; 87: 375-80$

18 Romagroli P, Filipponi F, Bandettini L, Brugnola D. Increase of mitotic activity in the colonic mucosa of patients with colorectal cancer. Dis Colon Rectum 1984;27:305-8.

19 Medawar PB. The rate of penetration of fixatives. $J R$ Microsc Soc 1942;61:46-57.

20 Baker JR. Principles of biological microtechnique. London: Methuen, 1960. 